\title{
Parental involvement in Primary School Education in Cyprus: What do the main stakeholders say?
}

\author{
Maria Savva \& Loizos Symeou \\ European University Cyprus - Cyprus
}

\begin{abstract}
This paper presents the findings of the first part of a three-stage mixed method research study which investigates parental involvement in primary school education in Cyprus, and in particular the role of parents in this sector of education of Cyprus. The findings presented in this paper are based on the analysis of four interviews from major stakeholders in Cyprus. The interviewees consisted the former Director of Primary School Education, the Chairman of Cyprus Primary Schools Teachers' Union, the Chairman of the Pancyprian Confederation of Parents' Association of Primary School Education, and the Chairman of the Pancyprian School of Parents. The paper discusses how those involved in policy and decision-making perceive parental involvement in the primary school education sector in Cyprus and highlights that even though this study is the first to investigate the issue among the involved stakeholders there is a lack of change in the field compared to other studies published in the last 25 years in Cyprus and especially as far as parental involvement in decision-making and policy influence.
\end{abstract}

Keywords: Parental involvement, decision-making, Primary Education.

\section{Participación de los padres en la Educación Primaria en Chipre: ¿Qué dicen las principales partes interesadas?}

\section{RESUMEN}

Este artículo presenta los resultados de la primera parte de un estudio compuesto de tres secciones desarrolladas con una metodología mixta de investigación, en el que se explora la participación de los padres en la Educación Primaria en Chipre; en particular, el rol que desempeñan. Es el primer estudio en Chipre que investiga este tema tomando en consideración la perspectiva de los principales agentes involucrados. Los resultados presentados en este documento se basan en el análisis de cuatro entrevistas a representantes de entidades clave de esta temática en Chipre: el ex Director de Educación Primaria, el Presidente del Sindicato del Profesorado de Educación Primaria de Chipre, el Presidente de la Confederación Panchipriota de Asociaciones de Padres de Educación Primaria y el Presidente de la Escuela de Padres Panchipriota. El documento analiza cómo perciben estos representantes que tienen funciones en la gestión y toma de decisiones sobre políticas educativas, la participación de los padres en la Educación Primaria en Chipre. Del análisis realizado se destaca que no se han producido cambios al comparar la situación actual con la descrita en otras publicaciones de Chipre de hace 25 años, especialmente en lo que se refiere a la influencia y participación que tienen los padres en la toma de decisiones sobre políticas educativas.

Palabras Clave: Participación de los padres, toma de decisiones, Educación Primaria.

\section{Introduction}

Family-school relationship has been a major concern for researchers worldwide in recent decades. Parental involvement is considered to be an element of effective education since it has positive outcomes for children, parents and teachers (Epstein, 2001; Hill \& Taylor, 2004; Hornby \& Lafaele, 2011; Mattingly et al, 2002; Peňa, 2000; Reininger \& López, 2017; Symeou, 2005). Extensive research and theoretical proposals stress the importance of parental involvement and identify the reasons affecting parents' decision to become involved, the practices that encourage or act as barriers to parental involvement, and its outcomes and impact. At the same time, studies carried out internationally pose questions as to whether parental involvement has only positive results, whether there is direct or indirect effect of such impact and whether the advantages or practices proposed for more active engagement can be implemented in all countries. Practices on parental involvement and the implementation of relevant policies followed by schools do not seem to encourage the development of positive school- 
family relationships for all students and certainly not for migrant and minority groups of students and their parents from specific social classes (Crozier \& Davies, 2007; Goodall \& Montogomery, 2014; Lehmann, 2018; Smit \& Driessen, 2005; Symeou, 2005; Theodorou, 2007).

Several theoretical models of parental involvement have been proposed to explain its significance, for instance HooverDempsey's \& Sandler's (1997) five-level model and Greenwood's and Hickman's (1991) model of five different types of parental involvement. The most widely used model of parental involvement internationally is the one proposed by Epstein et al. $(1995,2001)$ who distinguish six types of parental involvement that bring together schools, parents, and the local community in an integrated way, namely parenting, communicating, volunteering, learning at home, collaborating with the community, and participating in decision-making.

This paper presents the findings of the first part of a threestage mixed method research study that investigates parental involvement in primary school education in Cyprus. The paper focuses on the analysis of interviews from major stakeholders in primary education in Cyprus. This is the first and only published study to investigate the issue among policy-involved stakeholders in Cyprus.

\section{Parental Involvement in Cyprus}

Despite the large body of research on parental involvement worldwide, not much research has been conducted in Cyprus. Most of the existing studies examine mainly the beliefs and attitudes of teachers towards parental involvement (Georgiou, 1996; Phtiaka, 1996; Symeou, 2002). The lack of any recent legislative action in relation to the issue is indicative of the lack of substantial relations between families and schools (Symeou, 2010). In addition, there has been little research to explore the extent of active involvement of parents. There have been a few short pilot programmes or action research case studies, which investigated the impact of parental involvement practices on the school personnel, the families, and the pupils (Georgiou \& Tsouris, 1997; Symeou, 1997).

Georgiou (1996) classified school-family relationships in Cyprus into two general types: the formal and informal relationships. Formal relationships could include those provided through legislative ruling. These include the establishment and activity of schools' Parents Association, a 'parents' weekly visiting period' for parents to meet their children's teachers, and two evening events for families. Informal relations may include all the informal relationships between individual family members and schools. Among Cypriot primary schools, it appears that schools with a small population and rural schools, as opposed to bigger and non-rural schools respectively, seem to have stronger links with families, with significantly more teacher-family contacts, opportunities for exchanging information and invitations to families to offer voluntary labour (Georgiou, 1998; Symeou, 2001).

Despite these relationships, there is evidence to suggest that Cypriot parents are willing to come closer to the school; this indicates that there is a gap between their needs and their schools' programmes and practices (Georgiou, 1996, 1998; Symeou, 2001; 2010). Simultaneously, parents seem to be experiencing great ignorance and confusion on how this could be accomplished (Phtiaka, 1996). However, their perspectives and evaluation of specific practices aimed at linking them with schools still point to mild modes of involvement (Symeou, 2001; 2002).

Teachers in Cyprus seem to have a conservative attitude towards family involvement in schools. Like teachers in other countries, they generally seem to encourage school-family relationships and recognize its theoretical benefits, but determine the nature and extent of family engagement in the school so as not to threaten their schoolwork and professional status (Georgiou, 1996; Symeou, 2002). Evidence also shows that teachers of lower grades or of classes smaller in numbers seem to be linked with their pupils' families in a greater variety of ways (Symeou, 2001).

Given the focus of this study on the participation of parents in decision-making, the following section of the paper presents the opportunities provided for parents in the primary education sector in Cyprus to become involved in decisionmaking structures, namely through their participation in Parents' Associations. Parents' Associations (PA) in Cyprus work on a three-tiered basis; at the individual school level, at the regional level, and the national/pancyprian level (The Parental Associations Law of 1992, 105(I)/1992).

\section{Parents' Associations in Cyprus}

Parents' Associations are a recent phenomenon in Cyprus, which according to Symeonidou (2007) is attributed to the particular historical, social and political conditions that prevailed on the island. The unstable political past of the island (almost 300 years of Ottoman occupation and 80 years as an English colony) had a significant impact on both the family structure, the educational level and the professional activities of the island's inhabitants. Until 1974, most of the island's inhabitants were engaged in agriculture, while the majority of students left school before the last grades of primary school to help with agricultural work. The percentage of residents of the island who continued their studies after high school was very small and most of them were usually males. After the Turkish invasion in 1974, there is a shift towards education that is considered as a means of professional rehabilitation and improvement of living conditions (Symeonidou, 2007).

Nowadays, each of the 300 public primary schools in Cyprus has its own PA. All parents or guardians of pupils attending a primary school are automatically deemed to be members of the parents' association of their school by paying an annual fee. Each association elects its board at the beginning of each schoolyear. All parents have the right to elect and be elected if they have paid their annual subscription. The main aim of PAs is to provide in cooperation and coordination with the school the best possible education and school environment for the pupils. Its most important goals are to encourage communication and collaboration among school and families, and engage in activities, including fundraising, which support the infrastructure of schools and advance the education of the pupils attending the school (e.g. during most recent years, interactive boards, projector, laptops, tablets, etc.). PAs also organize seminars for parents and voluntarily assist school activities and events (Ministry of Education and Culture, Founding Association Statute). Each PA board has monthly meetings, where usually the school head teacher is invited to attend, in order to inform parents about the activities of the school, programs and other related issues. A (different) member of the board of each PA represents parents in three different school committees: a) Safety and health committee, where issues related to the safety of the pupils, especially for the case of disaster or emergency are discussed, and preventive measures are taken for the well-being of all pupils; b) the Advisory Committee, which meets at least twice a year and its main task is to define the needs of the school and make written recommendations about the improvement of the facilities of the school to the Ministry of Education and 
Culture (MoEC) through the District Education Office (circulars dde735 \& dde875); and c) the Canteen Committee which regularly inspects the quality of products and if the conditions and prices compile with the directions of the MoEC (http://www. MoEC.gov.cy/dde/en/index.html). A member of the board of each PA represents each school at its district Parents' Association (The Parental Associations Law of 1992, 105 (I)/1992).

All schools' elected PAs are automatically members of the District Parents' Association. There are six District Parents' Associations (DPA), each one representing one of the six geographical/administration districts of the country. In turn, all District Parents' associations are members of the Pancyprian Confederation of Parents Associations of Primary Education (PCPAPE) with two of their representatives participating in the General Secretariat of the Confederation (The Parental Associations Law of 1992, 105 (I)/1992).

The Pancyprian Confederation of Parents' Associations of Primary Education, which represents all parents of the almost 50,000 primary students, was founded in 1968. The board of the confederation has 36 members. In collaboration with the MoEC, the Pancyprian Union of Greek Teachers (POED), local authorities and other organisations, it aims to contribute in the development of policies and decisions that promote the highest possible quality of education for all primary students in Cyprus. Its main goals are to support the advancement of effective educational development and to promote and advocate for the active involvement of parents as primary educators of their children (Ministry of Education and Culture, Founding Association Statute). When issues related to the education in general are discussed or improvement plans are made at the MoEC, at the House of Representatives and other committees, parents are represented by members of the board of the Pancyprian Confederation of Parents Associations of Primary Education.

The Pancyprian Confederation of Parents Associations of Primary Education has been a full member of the Europeans Parents' Association (EPA) around two decades. Members of the Board of the Confederation attend the two annual meetings of EPA, representing all parents of pupils of primary education. The Pancyprian Confederation hosted the last meeting of EPA members in Paphos in April 2017.

Parents' representatives at the national level constitute a significant power-group and manage to influence the official educational policy (Georgiou, 1996; Symeou, 2010), despite this not being officially guaranteed through any relevant national legislation. There is also some evidence to show that families having a member in a school's PA are among those parents that Phtiaka (1996) classifies as parents who are 'close' to school and feel very confident with this contact and who according to Symeou (2001) are likely to be privileged in having more close contact with their child's teacher, to have their voice heard more and to have more opportunities to get involved in the school.

Another important body is the Pancyprian School for parents which was founded in 1968. It is the only official body where all the stakeholders of education are represented in its board. The aim of this organization, as it is defined by its statute, is to encourage parents to become active partners in schools, to educate parents on how to better raise their children, how to assist their children in learning and how to help their children maximize their potentials. In order to achieve its goals, it offers lectures and seminars, organize workshops and conferences and publish a two-monthly magazine.

This paper investigates major policy stakeholders views on parental involvement in primary school education in Cyprus.
The study is the first one in Cyprus aiming at depicting the views of the representatives of the main policy stakeholders in primary education. In more specific, the study aimed to answer the following four main research questions: How do policy stakeholder representatives perceive parental involvement in primary education in Cyprus?, How do these stakeholder representatives define the role of parents?, How does parental involvement in primary education in Cyprus does takes place according to the views of these stakeholder representatives?, and What problems arise in relation to parental involvement in primary education in Cyprus?

\section{Method}

In the light of the study's research questions, a qualitative study was conducted with a sample of four policy stakeholder representatives. The research approach was interpretive and the data were collected from individual interviews followed by a descriptive content analysis approach using inductive coding techniques.

\subsection{Participants}

The study was conducted in 2017. The sample of the survey was selected by typical sampling. The criterion for the selection of participants was the position the interviewee held in one of the main stakeholder establishments in education, namely the former Director of Primary School Education, the President of Cyprus Primary Schools Teachers' Union, the Chairman of the Pancyprian Confederation of Parents' Association of Primary School Education, and the Chairman of the Pancyprian School of Parents.

The Director of Primary Education in Cyprus heads the Department of Primary Education and is responsible for the organization, administration and the overseeing and monitoring of the functioning of Primary, Pre-Primary and special education schools, the schools of the Cyprus Educational Mission in the UK, the Adult Education Centres, and the Educational and Summer Camps. S/he is the one responsible for the organization, administration and the overseeing and monitoring of the Primary Education teaching staff and inspectorate. In addition, $\mathrm{s} /$ he is in charge of the planning and coordination of the work carried out in schools, as well as, the work carried out by the Primary Education Inspectorate; s/he is also accountable for the organization of educational conferences and training for Primary Education teaching staff and the consultancy on issues related to Primary Education (Ministry of Education and Culture, 2018).

The Chairman of Cyprus Primary Schools Teachers' Union is the head of the board of Primary and Pre-primary education teachers Union, which represents more than 5000 teachers in Cyprus (POED, 2018). The aim of the Union is mainly the upgrading of Education and Teachers. The board of the Union in cooperation with the MoEC, other educational bodies and Associations (parents' associations are considered to be among them) aim at promoting and safeguarding the professional interests of its members, securing and providing its members with professional, social and economic benefits and looking after the well-being of its members and the overall improvement in their living conditions (POED, 2018).

The Chairman of the Pancyprian Confederation of Parents' Association of Primary School Education and the Chairman of the Pancyprian School for Parents are the heads of the boards of the Confederation and the School respectively, whose aims and structure were presented in detail in the previous section. 
However, it should be noted that there is close cooperation among all the above bodies in designing reform plans and the implementation of any policies and decisions.

\subsection{Dimensions analyzed and instrument to gather information}

Aiming at recording the beliefs, attitudes and define the degree of involvement of parents in primary education in Cyprus as expressed through the views of representatives of the main policy stakeholders of education, a semi-structure interview schedule/protocol was prepared. The interview schedule requested the responses of the interviewees as to the meaning and scope of parental involvement in primary education in Cyprus, the role of organized and non-organized parents, the rights and obligations of parents in education, suggestions for the enhancement -if needed- of parental involvement in primary education in Cyprus. Emphasis was placed on the perceptions and views of the stakeholders' representatives on the role of parents, their involvement, their views on the factors that encourage or discourage school engagement, teachers' training and legislation on parental involvement in Cyprus.

At the same time, documents of the four stakeholders were used to triangulate the themes that emerged through the interviews. Specifically, the analysis used information from the relevant legislation, circulars of MoEC, the statutes of the Parents' Associations, the Annual reports of the Federations and the Confederation of Primary Education, the Reform Plans of education, as well as publications and announcements from the stakeholders' websites.

\subsection{Procedure for data gathering and analysis}

All interviews were conducted between March and April 2017. The interviews were recorded with the consent of the participants and then transcribed verbatim in order to minimize the possibility of loss or falsification of elements. The written texts were then analyzed and encoded. Due to the small number of interviews no qualitative software was used. The initial analysis was based on the key points as outlined above but was then modeled as discussed in the next section. The presentation of the topics is based on the documentation of extracts in the mother tongue of the participants.

\section{Results}

All four representatives of the main stakeholders, who participated in the interviews, namely the former Director of Primary School Education, the Chairman of Cyprus Primary Schools Teachers' Union (POED), the Chairman of Pancyprian Confederation of Parents' Association of Primary Education (PCPAPE) and the Chairman of the Pancyprian School for Parents, maintained that parental involvement plays a crucial role for the educational system of primary education in Cyprus.

In more specific, they claimed that parental involvement is closely linked to the effectiveness and the quality of the provided education. At the same time, it is remarkable that all interviewees recognized the role of parents at decision-making level and the implementation of changes. It turns out that both, teachers and parents focus on the same educational problems (general but also specific issues). The main concern of the stakeholders seems to be the improvement of the learning outcomes of students and to combat delinquency. There was also a consensus on the major issues of education, such as the evaluation of teachers and pupils, the National curriculum and the new system of teachers' appointment. At the same time, all stakeholder representatives identified the lack of in-service training about parental involvement, the weaknesses of existing legislation dealing with parental involvement and the important role of school directors to actively engage parents in their children's education.

All interviewees defined parental involvement as schoolfamily collaboration at the school level. They referred to practices that are mainly adopted by schools, such as teacherparents meetings, events organized or co-organized by teachers and parents, and lectures. They also emphasized that parents offer voluntarily their help and financial support. They also supported that parental involvement encompasses active parental involvement in District Parents Federations and the Pancyprian Confederation.

In particular, the Chairman of POED stated that parental involvement is an essential element of an effective educational system. He connected parental involvement with positive learning outcomes, improved students' behavior and positive school climate. In a relevant question, he stressed that:

"It is obvious ... you go to a school and you realise that the Parents Association is working together with the teachers".

The Chairman of POED defined school-level family involvement through terms such as collaboration, communication, information and co-organization of events. He identified the need for parents to inform school about any problems or difficulties his/her child faces and cooperate with the school in order to help the student. At the same time, he stressed the need that schools must "open" their doors to parents. He asserted that when parents are properly informed about teacher's methodology and requirements, is much easier to understand what the teachers do at school and at the same time suspicion and avoid conflicts.

As he pointed out:

"... with communication we build bridges and overcome problems and difficulties, to the greatest possible extent".

The Chairman of the Pancyprian Confederation of Parents' Association of Primary School Education stated that he believed that:

"We [organised parents] consider ourselves as one of the three most important stakeholders of education. As one of the most wellknown Cypriots professional in the field of education once said: "Schools exist because there are students to attend them". In the light of that statement, we believe that our role is really important at all three levels: school, district and Pancyprian [i.e. national] level. Parents should be active partners in the education of their children".

\subsection{Parents as a pressure group}

Parents' Associations and the Pancyprian Confederation are considered by the interviewees as a pressure group that affects educational activities. It transpires through the interviews that both, the MoEC and POED have long been seeking cooperation and support from parents in promoting change, innovation and reform. Specifically, the former Director of Primary Education stressed in a question from the researcher that:

"The policy of the ministry was [...] all Ministers always wanted the cooperation of parents, and always the instructions we had were to take care of good relations, not for the show but for the 
essence. So, there has always been a policy to be.... to respect the parents, to use them and to move together".

In a relevant question the Chairman of POED noted that:

"I think that nothing can be done in education...without parents' cooperation ...the teacher cannot be on one side and the parent on the other".

He thus recognized the importance of parents' support and approval in any measures or policies adopted or promoted by the teachers, and added:

"That's why ....I have to be honest [........] that what we were doing we always wanted parents' consent......we wanted them to be on our side".

\subsection{Teacher professional development on parental involvement and the role of the director}

TheMoEC is the competent authority for thein-service training and education of teachers through training activities, seminars and workshops organized mainly by the Pedagogical Institute. However, a few training modules aim at educating teachers on good practices to promote more active parental involvement. On the official website of the Pedagogical Institute, where all the thematic modules for in-service training are mentioned (the last three school years), there is not a single training module that focuses only on family-school relationships. However, on specific modules concerning school climate and delinquency there are sub-sections that specifically relate to school-family relationship and the role of parents, as well as practices that would help teachers enhance parental involvement.

All interviewees stressed the lack of proper teachers' inservice training of parental involvement. It seems that there is a necessity to introduce thematic modules directly into the professional development programs promoted by the MoEC, which will inform teachers about the advantages of parental involvement while familiarizing them with all those practices that will help them recognize the peculiarities of parents, encourage and promote more active parenting.

The Chairman of POED stressed that the issue of parental involvement and the practices followed by teachers to promote effective involvement depends mainly on the teachers' own experiences and personality and those of the director of each school, while stressing the lack of proper training. In particular, he stated that:

"Head teachers and teachers are not informed or educated about issues related to parents...it depends on each ones' experiences... One of the seminars during the two-day professional development program in September should be about parents. They should invite experts in the field to talk to teachers and persuade them....even POED could help the directors by showing them how to react in certain situations".

The Chairman of the Pancyprian Confederation of Primary Education shares the opinion of the Chairman of POED. Based on his experiences he claims that teachers follow practices based on their own experiences, their personal interest and their personality. As he said:

"I don't think that all teachers know a lot about parental involvement. Some of them are so positive whereas some of them find it really difficult to communicate and cooperate with us".
At the same time, he pointed out the lack of training and stressed the responsibility of the MoEC to organise training courses for all teachers. He said:

"...it is not our responsibility but the ministry has to find a way to educate them about the whole issue".

The former Director of Primary Education also identified the possibility of improving teachers' training programs. In more specific, he noted that all teachers are well trained on their subject, but they have not been trained for parental involvement issues either during their studies or through in-service training programs. Referring to the subject, he explained that:

"Teachers are well- trained on their subject and .... in methodology and so on, I do not think they have the appropriate training, I think there is always room for improvement.

The situation can be improved... There are still many teachers who are suspicious of parents involvement...they believe that parents criticise their work...So there is still much work to be done so that teachers come to realize that parental involvement can be mutually beneficial for students and teachers".

The Chairman of the Pancyprian School of Parents stressed that through his many years of experience as a teacher and as Chairman of the Pancyprian School of Parents, that teachers do not follow the same practices. There are neither clear guidelines set by the MoEC and nor teachers are trained enough on that matter. He stated that:

"As far as the question on how to involve parents there is a field of training and it would be good to make them......let's say teacher training".

Proper teacher training will ensure more parental engagement and reduce inequalities among schools that exist today.

The data analysis highlighted the role of the headteacher in the creation of a welcoming school culture was identified as of extreme importance. For instance, the Chairman of Cyprus Primary Schools Teachers' Union expressed the opinion that:

"The responsibility lies mainly on the headteacher of the school, who should be able to persuade the teaching staff of the school about the benefits [...] and if the headteacher and teachers work together with the PA of the school, then the rest of the parents will become active too".

According to what he said, it is up to the director to persuade his staff to promote practices that encourage parents to engage, to establish good relationships with the Parents' Association and then to cooperate with everyone to involve all parents.

The Chairman of the Pancyprian Confederation of Primary Education also pointed out that the degree of involvement depends entirely on the school. The attitude of each school's management determines through the practices that are followed family-school relationships. At the same time, he noted that parents need to feel welcome and be asked to get involved. Specifically, he claimed that:

"No matter how much we want to be involved in the school and help in activities or organise events, nothing can be done unless invited by the headteacher and the teachers. Parents need to feel welcome in order to go to school and offer their help". 
And continued by noting that:

"In most schools, involvement means financial support and voluntary help in activities that the school organises. We want more than that ...we want to be actual partners, to feel free to express our views on important matters about school and co-organise activities and events, ...not just subsidize events and activities decided by the teachers".

The former Director of Primary Education explained that it is the duty of the directors to take the initiative to involve parents. As he clarified, the director must persuade even those who are not willing to cooperate. On the subject, he specifically mentioned:

".... I expect that the directors themselves first engage parents so that with their cooperation we have the best results ........... many teachers do not accept it completely because they consider that involvement of parents is not necessarily positive..... in many cases it creates problems".

The Chairman of the Pancyprian School of Parents said on the subject that:

2I think that both have a responsibility, but mainly school and school management [........] but mainly at this point the director and his / her management team play a role in order to have a good cooperation with parents [........] Schools must open their doors to parents and society".

\subsection{Adequacy of relevant legislation - Rights and obligations of parents at all levels}

All four participants in the interviews expressed the opinion that the existing relevant law legislation is inadequate and that modifications are needed. It is now imperative that legislation be improved as they all stressed so that the obligations and rights of parents at every level are clearly stated. It is worth mentioning that nowadays at school level is determined through the circular that is sent for the start of the school year, but is not included in the school's regulations.

In more specific, the Chairman of the Pancyprian Confederation stated that parents are now pleased with their participation in decision-making, despite that that this involvement is not regulated, it is up to the Minister of Education. He actually mentioned that:

\footnotetext{
"We are really pleased that we have been given the chance the last few years to take part in meetings at the MoEC and had the chance to express our views on many aspects of education, but unfortunately that depends mainly on the Minister. The present Minister really appreciates our role and encourages our involvement even at the higher level...where all decisions are taken. But what will happen if a new Minister does not accept or appreciate our role? The law should be changed. The members of the House of Representatives in Cyprus should deal with the topic seriously".
}

Legislative enactment of parents and the defining of their role and responsibilities, is a matter that is recorded both in minutes of meetings and annual reports since 1976. Initially, there was a simple reference, but since 1989 the parents' request has remained the same. As stated in the 1989 Annual Report of the Confederation (PCPAPE, 1989), there is a need "To add to the Law a special article defining the role of the Organized
Parents and their relations with all Stakeholders involved in Education, and related subjects such as health, safety, prosperity, entertainment, etc. of students, so as not to relieve the state of its responsibilities for the education of our country" (p. 9). Since that year it has been recorded that "the role of the Organized Parents depends entirely on their relations with all other stakeholders" (PCPAPE, 1989, p. 9).

The former Director of Primary Education also identifies the weakness of regulations and legislation related to parental involvement and the need to promote changes to ensure parental participation at all levels. In a specific question he stated that:

"But I believe that there is still a lot of room in legislation to strengthen the role of parents ...... So it is necessary to modify and strengthen legislation and regulations so as to give a more institutional role to parents [........] there is room for improvement in this area because I am aware that there are many things in school regulations regarding the role of organized parents which are missing".

The Chairman of POED also claims that there is room for improvement of existing legislation and regulations by placing responsibility on the MoEC. In a relevant question he replied that:

"... there is room for improvement, there is room for improvement.

The demographic characteristics of parents as a factor determining the degree of involvement".

Although not many questions in the interview protocols focused on parents and family characteristics in relation to parental involvement, all interviewees brought this issue repeatedly during the interview. More specifically, all interviewees suggested that parents' gender, the place where they live or parental level of education do not actually affect the quality and level of involvement.

According to the former Director of Primary Education, what matters is the personality of the parents and not their educational level. As he pointed out:

"... I do not say that parents who are more educated necessary develop the right relationship with the school ... I would say that it is more a matter of personality".

The Chairman of the Pancyprian Confederation of Primary Education appeared to agree with the former Director of Primary Education regarding the educational level and the level of parental involvement. He also added that in his opinion, neither leisure time nor the area where families stay seems to play a crucial role. The interviewee himself focused on the fact that all the stakeholders involved in education have failed to persuade or encourage parents to be involved. He emphasized that:

"I think that parents' involvement is not that much related to their level of education or how much free time they have...even the place where they live may not be related. I think we haven't managed to persuade them that they should be involved in their children's education...it's an obligation...their children gain so much..."

Being involved though, in the school's PA or not, was according to the Chairman of the Pancyprian School for Parents a determinant factor in involvement in school and particularly in attending lectures, seminars, workshops or conferences. Parents 
participating in parents' associations are much more involved in training activities and are usually engaged in organizing such events. The problem, as he stated, is to involve all other parents in training activities. As he said:

"The parents who are members of the boards of either the PA of their school, the District Parents' Association or the PCPAPE, show great interest in attending and organizing lectures, conferences, and workshops. The problem is to persuade the rest of the parents to attend these events. It is still a problem that we have not managed to solve..."

He also supported that the age of the child is also a determinant factor on whether or not a parent is involved. As he suggested, the younger a child is the more his or her parents are willing to attend lectures and seminars. He said:

"Parents of children at pre-primary or the first stages of primary education show greater interest...maybe because they want to become better parents".

As can be seen both, from the above statement of the Chairman of the Pancyprian School of Parents and information from the archives of the Pancyprian School of Parents, the educational activities carried out by parents of primary education are three times higher than those carried out by parents of secondary and technical education. Also, the number of participants in such lectures or seminars, is also much higher in events involving parents of primary school students than those organized in secondary or technical education.

\section{Discussion and Conclusions}

Active and effective involvement of parents has been claimed to be an integral element of educational systems if aiming at achieving children's full potentials; and schools in Cyprus cannot be an exception. The findings presented in this paper were based on the analysis of four interviews from primary education major policy stakeholders in Cyprus. The analysis of the interview data demonstrated how all interviewees agree on that parental involvement is a key factor to an effective educational system and that it can lead to initiatives aiming at strengthening parental involvement in education, as well as the development and implementation of policies that support such programs in schools.

All interviewees also stressed the importance of the school itself to be inviting and welcoming to parents and families in order for this to enhance parental involvement. As initial studies in the educational system of Cyprus claimed (Georgiou, 1996; Symeou, 2002), twenty years later it seems that the extent and nature of school-family relationships still heavily depend on how inviting the school itself is. The school head teachers' role was identified by all interviewees as vital in terms of the initiation and promotion of parental involvement and the establishment of a relevant ethos and culture. Thus, professional development both during in-service educational administration training or generic professional development programs were suggested to be needed and that they should include information and guidelines concerning parental involvement. Moreover, teachers' overall pre- and in-service training could include programs that deal with the positive outcomes of parental involvement and specific techniques to encourage parental involvement. In achieving this, further local research on the strategies that can be locally relevant and positively assessed by schools and parents can facilitate schools and teachers to enhance and avoid discouraging parental involvement as many international studies suggest (Epstein, 2018; Gomila, Pascual \& Quincores, 2018; Lenmann, 2018). Similarly, parents could also be educated too about the positive outcomes of parental involvement in order to be more active in school involvement. Schools and parents' associations can play a significant role in disseminating information on effective parental involvement.

Notably, the analysis of the data indicated the lack of relevant supporting legislation, as this appears to be identified for decades now (Georgiou, 1996; Symeou, 2010), and how the law legislation could be improved in order to ensure parental involvement at all levels. Although it has been foreseen that parental involvement has been increased in the last years, especially after the Reform Act of 2008 when it was decided to increase parental involvement in school activities from $10 \%$ to $30 \%$, the legislation has not changed decades now. What is notable is that even though members of the board of the Pancyprian Confederation of Parents' Association of Primary School Education do represent the last few years parents in various committees at the national/pancyprian level (e.g. Committee for the Revised Rules and Regulations of Primary Education, Committee for the Evaluation of the Implementation of Content and Language Integrated Learning-CLIL in Primary Education) and meetings (e.g. Education Council/ $/ \Sigma u \mu \beta o u ́ \lambda ı$ $\Pi \alpha \iota \delta \varepsilon\{\alpha \varsigma$, Primary and Secondary Education Council/

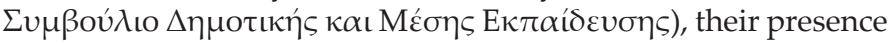
and participation in most of these committees or meetings depends on the will and personal decision of the Minister of Education and Culture. As all interviewees pointed out any formal participation of parents is not defined clearly by law and their involvement in policy and decision-making is still a matter of circumstances and the personal stance of the Minister of Education and Culture at the time. It thus appears that parental involvement at this sphere of the state primary education system is dependent on a possible discussion of new law legislation that would aim to ensure parental involvement at all levels.

\section{References}

Crozier, G., \& Davies, J. (2007). Hard to reach parents or hard to reach schools? A discussion of home-school relations, with particular reference to Bangladeshi and Pakistani parents. British Educational Research Journal, 33(3), 295-313. doi: 10.1080/01411920701243578

Epstein, J. L. (1995). School-family-community partnerships: Caring for the children we share. Phi Delta Kappan, 76(9), 701712.

Epstein, J. L. (2001). School, family, and community partnerships. Boulder, CO: Westview.

Epstein, J. L. (2018). School, family, and community partnerships in teachers' professional work. Journal of Education for Teaching, 44(3), 397-406. doi: 10.1080/02607476.2018.1465669

Georgiou, S. N. (1996). Parental involvement in Cyprus. International Journal of Educational Research, 25(1), 33-43. doi: 10.1016/0883-0355(96)82040-4

Georgiou, S. N. (1998). A study of two Cypriot school communities. The School Community Journal, 8(1), 73-91.

Georgiou, S., \& Tsouris, C. (1997). Partnership in education:

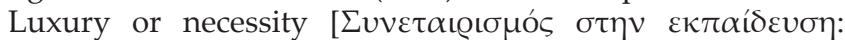

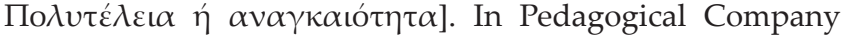
of Cyprus (Ed.), Cyprus Pedagogical Review [П $\alpha \mathrm{\iota} \alpha \gamma \omega \gamma \mathrm{\iota} \kappa \dot{n}$

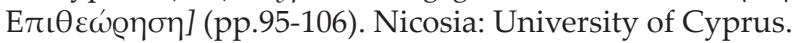

Gomila, M. A., Pascual, B., \& Quincoces, M. (2018). Familyschool partnership in the Spanish education system. 
Journal of Education for Teaching, 44(3), 309-320. doi: 10.1080/02607476.2018.1465641

Goodall, M., \& Montgomery, C. (2014). Parental involvement to parental engagement: a continuum. Educational Review, 66(4), 399-410. doi: 10.1080/00131911.2013.781576

Greenwood, G. E., \& Hickman, W. K., (1991). Research and Practice in Parent Involvement: Implications for Teacher Education. The Elementary School Journal, 91(3), 279-288.

Hill, N. E., \& Taylor, L. C. (2004) Parental school involvement and children's academic achievement: Pragmatics and issues. Current Directions in Psychological Science, 13(4), 161-164. doi: 10.1111/j.0963-7214.2004.00298.x

Hoover-Dempsey, K., \& Sandler, H. (1997). Why do parents become involved in their children's education? Review of Educational Research, 67, 3-42.

Hornby, G., \& Lafaele, R. (2011). Barriers to parental involvement in education: an explanatory model, Educational Review, 63(1), 37-52. doi: 10.1080/00131911.2010.488049

Lehmann, J. (2018). Parental involvement: An issue for Swiss primary school teacher education. Journal of Education for Teaching, 44(3), 296-308. doi: 10.1080/02607476.2018.1465626

Mattingly, D. J., Prislin, R., McKenzie, T.L., \& Rodriquez, Kayzar, B. (2002). Evaluating evaluations: The case of parent involvement programs. Review of Educational Research, 72(4), 549-576. doi: 10.3102/00346543072004549

Ministry of Education and Culture, Founding Association Statute. Retrieved on 24.11.2018 from: www.omospondiagoneon.com

Peňa, D. C. (2000). Parent involvement: Influencing factors and implications. The Journal of Educational Research, 94(1), 42-54. doi: 10.1080/00220670009598741

PCPAPE (1989). Annual Report of the Pancyprian Confederation of Parents Associations of Primary Education. Nicosia: Pancyprian Confederation of Parents.

Phtiaka, H. (1996). Each to his own? Home-school relations in Cyprus. Forum of Education, 51(1), 47-59.

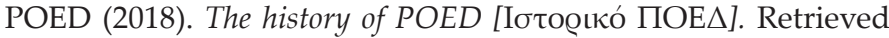
on 24.11.2018 from: https://www.poed.com.cy/Default. aspx?tabid $=58$

Reininger, T., \& Lopez, A.S. (2017). Parental involvement in municipal schools in Chile: Why do parents choose to get involved? School Psychology International, 38(4), 363-379. doi: $10.1177 / 0143034317695378$

Smit, F., \& Driessen, G. (2005). Ethnic minority parents' and teachers' orientation on collaboration between home and school: Strategies and contexts. Aula Abierta, 86, 169-184.

Symeonidou, S. (2007). Parental associations and education politics regarding disability: The case of Cyprus. International Journal about Parents in Education, 1, 164-173.

Symeou, L. (1997). Parental involvement in class E'1 of Aradhippou B' Primary School during the school year 1996-97. Paper presented at the conference of the Primary Schools of the district of Larnaca (Aradhippou, Cyprus, June 6).

Symeou, L. (2001). Family-school liaisons in Cyprus: An investigation of families' perspectives and needs. In F. Smit, K. van der Wolf, \& P. Sleegers, (Eds.), A Bridge to the future. Collaboration between parents, schools and communities (pp. 33-43). Netherlands: Institute for Applied Social Sciences, University of Nijmegen.

Symeou, L. (2002). Present and future home-school relations in Cyprus: An investigation of teachers' and parents' perspectives. The School Community Journal, 2(12), 7-34.

Symeou, L. (2005). Past and present in the notion of school-family collaboration. Aula Abierta, 85(1-2), 165-183.

Symeou, L. (2010). Teacher-family communication in Cypriot primary schools. Beau Bassin: VDM Publishing House.

Theodorou, E. (2007). Reading between the lines: exploring the assumptions and implications of parental involvement. International Journal about Parents in Education, 1, 90-96.

The Parental Associations Law of 1992 (105(I)/1992). Retrieved on 24.11.2018 from: http://www.cylaw.org 